\title{
Why Prices Don't Respond Sooner to a Prospective Sovereign Debt Crisis
}

\author{
R. Anton Braun and Tomoyuki Nakajima
}

\section{Working Paper 2011-13 \\ November 2011}

\begin{abstract}
We compare the dynamics of inflation and bond yields leading up to a sovereign debt crisis in settings where asset markets are frictionless to other settings with financial frictions. As compared with the case with frictionless asset markets, an asset market structure with financial frictions generates a significant delay in the response of prices to news about a future debt crisis. With complete markets, prices jump in response to news about the possibility of a future debt crisis. However, when short selling of government bonds is restricted, some agents can't act on their beliefs, and prices don't respond to the news. Instead, prices only move in periods immediately prior the crisis.
\end{abstract}

JEL classification: E31, E62, H60

Key words: sovereign debt crisis, deflation, fiscal risk, leverage, borrowing constraint

For helpful comments and suggestions, the authors thank Kosuke Aoki, Fumio Hayashi, Atsushi Kajii, Keiichiro Kobayashi, Masao Ogaki, Kozo Ueda, and seminar participants at the Bank of Japan, CIGS, Federal Reserve Bank of Atlanta, Hitotsubashi University (ICS), Kyoto University, and the University of Tokyo. Part of this research was conducted while Nakajima was a visiting scholar at the Institute for Monetary and Economic Studies at the Bank of Japan, whose hospitality is gratefully acknowledged. Nakajima thanks the financial support from the JSPS. The views expressed here are the authors' and not necessarily those of the Federal Reserve Bank of Atlanta or the Federal Reserve System. Any remaining errors are the authors’ responsibility.

Please address questions regarding content to R. Anton Braun, Research Department, Federal Reserve Bank of Atlanta, 1000 Peachtree Street, N.E., Atlanta, GA 30309-4470, 404-498-8708, r.anton.braun@gmail.com, or Tomoyuki Nakajima, Institute of Economic Research, Kyoto University and the Canon Institute for Global Studies, Yoshida-Honmachi, Sakyo-ku, Kyoto 606-8501, 81-75-753-7102, nakajima@kier.kyoto-u.ac.jp.

Federal Reserve Bank of Atlanta working papers, including revised versions, are available on the Atlanta Fed's website at frbatlanta.org/pubs/WP/. Use the WebScriber Service at frbatlanta.org to receive e-mail notifications about new papers. 


\section{Introduction}

Recently, many developed countries have faced serious government debt problems in the midst of severe and persistent economic contractions. It is a politically difficult task for a government to increase taxes or lower purchases and engineer a fiscal consolidation. For a government that fails to generate a fiscal consolidation the alternative is default. Default can arise in one of two ways. One way is to suspend payments on its debt. Most sovereign debt is nominally denominated. This opens the door to a second form of implicit default. High inflation reduces the real value of outstanding government debt. We refer to either of these forms of default as a sovereign debt crisis.

How does news about the possibility of a future debt crisis affect prices today? Under the assumptions of rational expectations and complete markets, prices will respond instantly to the news. This result is at odds with what we see in some major economies. In Japan the gross debt-GDP ratio has risen from 60 percent to over 200 percent and yet the yield curve is flat and the price level is falling. In the United States government debt has also risen sharply and yet bond yields are low and inflation is muted.

The fact that prices have not responded is comforting to policy makers. On the one hand, sharp increases in yields and/or inflation can be a powerful impetus for the fiscal authority to get its house in order. On the other hand, if prices don't respond, there is a tendency for policy makers to perceive that the problem is not severe and to kick the can down the road.

The fact that prices are not responding today does not mean that there is not a significant risk of a future default. The objective of this paper is to use a model to make this point explicit. We show that the asset market structure plays a crucial role in determining how prices respond to an increase in the risk of a debt crisis. If markets are complete prices respond sharply and immediately to news about a prospective debt crisis. However, the response of prices can be delayed when financial frictions are modeled. News about the prospect of a future crisis has no impact on current prices. Instead prices increase sharply only shortly before the crisis event.

We consider two models: one where default is implicit and another where default is explicit. The particular model of implicit default we consider is a variant of the fiscal theory of the price level (FTPL) studied, for instance, by Leeper (1991), Sims (1994), Woodford (1995), Cochrane (2001), and Bassetto (2002), among others. Following the convention of this literature, we suppose that the government sets a sequence of real tax revenue as well as a sequence of nominal interest rates. In equilibrium the price level adjusts to satisfy the government's flow budget constraint in every period. For simplicity, we consider a finite horizon model in which the government collects taxes only in the last period. The amount of taxes collected in the 
last period are either high, $T_{H}$, or low, $T_{L}$. The equilibrium price level in the last period is higher when the taxes collected in that period are smaller. We choose $T_{L}$ be so small that the equilibrium inflation rate is very large when the $T_{L}$ event occurs and refer to this outcome as a sovereign debt crisis.

Our model of beliefs and market structure builds on previous research by Geanakoplos (2003, 2010). Individuals have different beliefs about the probability of a debt crisis. When a debt crisis occurs, the inflation rate rises and, as a result, the ex-post real rate of return on government bonds falls. Thus, individuals who believe that the probability of a fiscal crisis is low are relatively optimistic about the rate of return on government bonds.

We examine the dynamics of the inflation rate under two asset market structures. The first structure is frictionless asset markets. Agents trade a complete set of contingent claims. In the second market structure contingent claims are not traded. Agents can borrow to purchase government debt, but short selling of government debt is ruled out. In the complete markets specification both optimistic and pessimistic agents can freely bet on their beliefs. Relatively optimistic agents buy the Arrow security which pays off in a state without a crisis and sell the Arrow security which pays off in a state with a crisis. Relatively pessimistic agents make the opposite trades.

In the second asset market structure, however, there is asymmetry between optimistic and pessimistic agents. On the one hand, optimistic agents borrow as much as possible to purchase government bonds. This transaction is similar to purchasing the Arrow security that pays off in the no crisis event. On the other hand, since government bonds cannot be short sold by assumption, there is no transaction that allows one to mimic the purchase of an Arrow security that pays off if there is a crisis. Pessimistic agents are not able to bet on their beliefs and lend to optimistic individuals instead.

The two asset market structures have very different implications for the dynamics of the inflation rate. If asset markets are frictionless news about the possibility of a future debt crisis gets immediately reflected in the price level and the inflation rate jumps up in the initial period. In subsequent periods the inflation rate remains high along the path leading to the debt crisis. In other words, there is a kind of inflation smoothing when asset markets are frictionless.

In our setup with financial frictions the reaction of the initial price level to news about the possibility of a future debt crisis is very small. In fact, in some of our examples the price response is indistinguishable from zero. Instead the inflation rate only increases in states that occur immediately prior to the crisis event. A final distinction is that the response of the inflation rate in the crisis state is much larger when there are financial frictions. 
The intuition for this result is simple. When asset markets are frictionless both optimistic and pessimistic agents can bet on their beliefs. In the presence of financial frictions, however, only optimistic individuals can do so. This results in a higher real price of government bonds and a lower inflation rate.

We also consider a setup with long-term debt and an exogenous price level. This is meant to capture the situation for a country such as Greece that is a member of a currency union. The results are very similar. In the complete markets specification with no financial frictions the yield on long-term debt jumps immediately in response to news about a future default. In the leverage specification, in contrast, the response of the yield curve to the same news is about zero. The yield on long-term debt does eventually rise but only immediately before the crisis event.

\section{Motivation for the model}

One of the most important implications of forward looking behavior is that news about future events influences actions and the price system today. In the context of our model, news that the risk of a debt crisis has gone up should result in price increases today. In Section 3 we will demonstrate this point with a formal model. Before discussing the model we first provide some empirical evidence that suggests that price responses to news is delayed.

A variety of papers have provided evidence that sovereign debt crises are predictable. Rheinhart and Rogoff (2010) find that the probability of a future sovereign debt crisis increases for countries that experience banking crises and large increases in government and external debt. Nieto Parra (2008) finds that investment banks demand higher underwriting fees as much as three years in advance of sovereign debt crises.

Bond yields, however, do not appear to respond contemporaneously. For intance, in Nieto Parra's (2008) sample of 29 emerging countries running from 1993 to 2006, bond risk premia for crisis countries are somewhat elevated but stable in the 5 year period leading up to the crisis and don't respond to higher underwriting fees.

Inflation also does not appear to react contemporaneously to higher public deficits. Bassetto and Butters (2010) report empirical evidence on the contemporaneous correlation of public deficits with inflation using a sample of OECD countries that extends from 19702009. ${ }^{1}$. They find no evidence that high public deficits are associated with higher inflation rates using their "corrected" measure of the deficit. ${ }^{2}$

\footnotetext{
${ }^{1}$ Their sample excludes some countries that experienced crises such as Mexico and Turkey.

${ }^{2}$ They adjust the standard definition of the deficit to recognize savings that accure to the government when
} 
Figure 1 reports debt-GDP ratios, the inflation rate, and short and long-term interest rates for 3 sets of country pairs. Korea is plotted with Japan, Canada is plotted with the U.S. and Germany is plotted with Greece. ${ }^{3}$ The reason for these choices of parings can be seen by comparing the evolution of the debt-GDP ratio in each country paring. Japan has seen the debt-GDP ratio rise from 50 percent in 1988 to over 180 percent in 2009. This debt-GDP is very high relative to other advanced economies. In Korea, in contrast, the debt-GDP ratio is very low. It gradually rises during the sample from a low of 13 percent in 1988 but is less than 32 percent in 2010. Recent research by Imrohoroglu and Sudou (2010) and Braun and Joines (2011) suggests that the current trajectory of government debt in Japan is unsustainable. If one accepts this view then there are four distinct ways that a fiscal consolidation could occur: higher real growth, a fiscal consolidation produced by higher taxes and/or lower government spending, higher inflation that devalues the real value of outstanding government liabilities or a payments suspension. What is surprising about Japan is that in spite of a near tripling in the debt-GDP ratio, there is no evidence of an uptick in either inflationary pressure or the yield curve. Yields on long-term bonds are falling throughout that sample and the economy has seen the inflation rate fall as the debt-GDP ratio increased and now finds itself in a situation with deflation. Observe also that both long-term bond yields and the inflation rate are lower in Japan than Korea, a country with a much stronger fiscal situation.

A similar picture emerges if we compare the U.S. with Canada. Between 2007 and 2010 the U.S. has seen the debt-GDP ratio increase from 36 percent to 61 percent. Canada also experiences an increase. The debt-GDP ratio rises from 25 percent in 2007 to 36 percent in 2009 but then stabilizes at about that level in 2010. One might expect that the large increase in U.S. indebtedness in conjunction with difficulties in legislating either higher taxes or lower government expenditures would lead agents to assign a higher probability to either an explicit payment suspension or higher inflation in the U.S as compared to Canada. However, as the plots in Figure 1 reveal, the evolution of inflation and long-term bond yields in the U.S. in Canada are virtually identical.

If markets assign very low or even zero probability to either explicit default or implicit default via inflation in the U.S. and Japan prices may not respond. It is thus also useful to consider an industrialized country which has experienced a debt crisis.

Consider the plots of Germany and Greece. Inflation rates are low in both countries after they switch to the Euro and remain low through the end of 2010. Galati, Heemeijer and

\footnotetext{
debt is nominally denominated and there is inflation.

${ }^{3}$ Our basic source for this data is OECD. In some cases this data has been supplemented with data from the IMF, the Bank of Japan and Bank of Greece. More details on our data sources can be found in the Appendix.
} 
Mossner (2011) find evidence that inflation expectations respond to increases in sovereign default risk in 2009 and 2010. However, these beliefs cannot be seen in inflation rates in Greece and Germany which remain low.

Between 2000 and 2007 the debt-GDP ratio in Greece was averaging a bit over 100 percent. This compared with a debt-GDP ratio in Germany of about 40 percent. In spite of this difference, the risk premium on Greek long term bonds was only 25 basis points on average between 2002 and 2007. Greece saw its debt-GDP ratio increase from 106 percent in 2007 to 148 percent in 2010. In December of 2008 the spread on long-term Greek debt over German debt rose above 2 percent for the first time since the Euro was founded. A bit more than 16 months later Greece requested funds from the EU/IMF in April of 2010.

This concentration of the price increases in states close to the crisis event also occurred in Argentina. Lau (2003) estimates one year ahead default probabilities for Argentina using credit default swap data and finds that the probability of default only starts rising in October of 2000 which was about 2 months prior to the IMF package which, was approved in December of 2000, and 15 months prior to its default in January of 2001.

Overall, this evidence raises the possibility of a disconnect between risk and price movements. In early periods as the risk of a future debt crisis increases price responses appear to be muted or even zero. Even though there are early indications that the probability of a debt crisis is increasing, prices only appear to react at most 12-16 months before the crisis. Our aim here is to formalize a specific explanation for these observations. We will next turn to illustrate that modeling financial frictions can have a first order impact on the timing and size of inflation and yield curve responses to a debt crisis.

\section{Two-period model}

A central message of this paper is that the market structure has first order implications for the dynamics of the inflation rate. To illustrate this point we will characterize the competitive equilibrium under three different asset market structures. After that we will describe how the equilibrium inflation rate varies across them when agents begin to expect a debt crisis.

Our model is an exchange economy in which all agents consume a single consumption good in each period. To make our arguments more transparent we follow the example of the literature on the fiscal theory of the price level and abstract from money. The price level is determined as the relative price of the consumption good and the (nominal) government bond.

To make the exposition of the model more transparent to the reader we begin by consider- 
ing a two-period version of the model. Then in Section 4 we generalize the model to allow for an arbitrary number of time periods. Periods are indexed by $t=0,1$. There are two states of nature in period 1, $U$ and $D$. As discussed below, they are distinguished by the amount of taxes collected by the government. In this two period model the event $D$ will be associated with low taxes and a debt crisis. We let $s_{t}$ denote the state of nature in period $t$, where $s_{0}=0$ and $s_{1} \in S \equiv\{U, D\}$.

Individuals: There is a continuum of agents indexed by $h \in[0,1]$. Each agent receives an identical endowment of $y_{t}$ units of the consumption good in period $t=0,1$. Note that the endowment does not depend on the state in period 1. Agents are also endowed with equal amounts of nominal government debt, $\bar{B}>0$, in period zero. All agents have access to a risk-free storage technology that offers a gross rate of return denoted by $R>1$.

Agents are identical except for their beliefs about the probability that state $U$ occurs in period 1. Specifically, we assume that agent $h$ believes that $s_{1}=U$ with probability $h$. Thus, agents with high $h$ assign less probability to the debt crisis event. All agents have linear preferences of the form:

$$
c_{0}+\sum_{s_{1} \in S} \gamma^{h}\left(s_{1}\right) c\left(s_{1}\right)
$$

where $\gamma^{h}\left(s_{1}\right)$ denotes the subjective probability of agent $h$ that state $U$ occurs in period 1 :

$$
\gamma^{h}\left(s_{1}\right)= \begin{cases}h, & \text { for } s_{1}=U \\ 1-h, & \text { for } s_{1}=D\end{cases}
$$

Government: The government starts off with $\bar{B}>0$ nominal liabilities to the private sector, collects taxes and issues one-period bonds. We abstract from government consumption and assume that taxes are lump sum and identical across agents. Neither of these assumptions are essential to our arguments. Let $T_{0}$ and $T\left(s_{1}\right)$ denote the real amount of taxes in period 0 and in state $s_{1} \in S$ of period 1 , respectively. Let $B_{0}$ be the nominal amount of bonds issued by the government in period 0 and $q_{0} \in(0,1]$ be the price of those bonds. Given these definitions the "flow budget constraints" of the government in period 0 and in state $s_{1} \in S$ of period 1 
are given by ${ }^{4}$

$$
\begin{aligned}
\bar{B} & =P_{0} T_{0}+q_{0} B_{0}, \\
B_{0} & =P\left(s_{1}\right) T\left(s_{1}\right), \quad s_{1} \in S,
\end{aligned}
$$

where $P_{0}$ and $P\left(s_{1}\right)$ are the price levels in period 0 and in state $s_{1}$, respectively.

We will refer to the government's choice of $\left\{T_{0},\left\{T\left(s_{1}\right)\right\}_{s_{1} \in S}\right\}$ as its fiscal policy, and its choice of the one-period nominal interest rate $1 / q_{0}$ as its monetary policy. Given a particular choice of the nominal interest rate, the amount of government bonds issued in period $0, B_{0}$, is determined so as to satisfy demands from the private sector.

We assume that the government collects taxes in the following fashion:

$$
\begin{gathered}
T_{0}=0, \\
T\left(s_{1}\right)= \begin{cases}T_{H}, & \text { if } s_{1}=U, \\
T_{L}, & \text { if } s_{1}=D,\end{cases}
\end{gathered}
$$

where $T_{H} \gg T_{L}>0$. We assume that the amount of taxes collected by the government is very small in state $D$ in period 1 . This explains our use of the expression "debt crisis" to refer to this state. Thus a government policy is given by $\left(q_{0}, T_{H}, T_{L}\right) \in(0,1] \times \mathbb{R}_{++}^{2}$. We assume that government policy is exogenous.

\subsection{Complete markets}

Let us begin by considering a setting with complete markets and no trading frictions. We will subsequently refer to this as the complete markets specification. Suppose that a complete set of one period contingent claims (Arrow securities) are traded in period 0. Let $q\left(s_{1}\right)$ denote the price of an Arrow security that pays off one unit of account in period 1 if and only if $s_{1}$ occurs.

Each agent $h \in[0,1]$ maximizes utility (1) subject to the budget constraints:

$$
\begin{aligned}
& c_{0}+k_{0}+\sum_{s_{1} \in S} q\left(s_{1}\right) \frac{b\left(s_{1}\right)}{P_{0}}+q_{0} \frac{b_{0}}{P_{0}} \leq \frac{\bar{B}}{P_{0}}+y_{0}, \\
& c\left(s_{1}\right) \leq R k_{0}+\frac{b\left(s_{1}\right)}{P\left(s_{1}\right)}+\frac{b_{0}}{P\left(s_{1}\right)}+y_{1}-T\left(s_{1}\right), \quad s_{1} \in S, \\
& c_{0}, k_{0}, b_{0}, c\left(s_{1}\right) \geq 0, \quad s_{1} \in S,
\end{aligned}
$$

\footnotetext{
${ }^{4}$ Here we refer to (2)-(3) as the flow budget constraints of the government. But, as is well known, in the standard formulation of the fiscal theory there is ambiguity about exactly what constraints the government faces. Bassetto (2002) posits a game theoretic version of the fiscal theory that removes this ambiguity. It is straightforward to rewrite our model in the same way as Bassetto (2002).
} 
where $k_{0}$ is the amount goods stored in period $0, b_{0}$ is the amount of government bonds purchased in period 0 , and $\left\{b\left(s_{1}\right)\right\}_{s_{1} \in S}$ are the amounts of Arrow securities purchased in period 0. Notice that (8) imposes a short selling restriction on government debt. Given that agents have access to a complete set of one period Arrow securities this restriction doesn't matter in this setting. Having described the agent's problem we can now define a competitive equilibrium.

Definition 1 (Complete Markets Competitive Equilibrium). Given a government policy $\left(q_{0}, T_{H}, T_{L}\right)$, a complete markets competitive equilibrium consists of an allocation $\left\{c_{0}^{h},\left[c^{h}\left(s_{1}\right)\right]_{s_{1} \in S}\right.$, $\left.k_{0}^{h}, b_{0}^{h},\left[b^{h}\left(s_{1}\right)\right]_{s_{1} \in S}\right\}_{h \in[0,1]}$, supply of government bonds $B_{0}$, and prices $\left\{P_{0},\left[P\left(s_{1}\right)\right]_{s_{1} \in S}\right.$, $\left.\left[q\left(s_{1}\right)\right]_{s_{1} \in S}\right\}$ such that (i) for each agent $h \in[0,1]$, the allocation $\left\{c_{0}^{h},\left[c^{h}\left(s_{1}\right)\right]_{s_{1} \in S}, k_{0}^{h}, b_{0}^{h}\right.$, $\left.\left[b^{h}\left(s_{1}\right)\right]_{s_{1} \in S}\right\}$ solves her utility maximization problem; (ii) the government flow budget constraints (2)-(3) are satisfied, where taxes $\left\{T_{0},\left[T\left(s_{1}\right)\right]_{s_{1} \in S}\right\}$ are given by (4)-(5); and (iii) all markets clear:

$$
\begin{aligned}
& \int_{0}^{1}\left(c_{0}^{h}+k_{0}^{h}\right) d h=y_{0}, \\
& \int_{0}^{1} c^{h}\left(s_{1}\right) d h=y_{1}+R \int_{0}^{1} k_{0}^{h} d h, \quad s_{1} \in S, \\
& \int_{0}^{1} b_{0}^{h} d h=B_{0}, \\
& \int_{0}^{1} b^{h}\left(s_{1}\right) d h=0, \quad s_{1} \in S .
\end{aligned}
$$

We now turn to provide a characterization of the complete markets equilibrium. In this setting both storage and the government bond are redundant assets. Since the government bond pays off one unit of account irrespective of the state in period 1, no-arbitrage requires that

$$
\sum_{s_{1} \in S} q\left(s_{1}\right)=q_{0}
$$

Similarly, since one unit of goods put into storage in period 0 yields $R$ units of goods in all states in period 1, no-arbitrage also implies

$$
\sum_{s_{1} \in S} \frac{q\left(s_{1}\right) P\left(s_{1}\right)}{P_{0}} R=1
$$

when storage occurs in equilibrium.

It follows from these observations that the flow budget constraints (6)-(7) can be combined to obtain the lifetime budget constraint:

$$
R c_{0}+\sum_{s_{1} \in S} \frac{q\left(s_{1}\right) P\left(s_{1}\right)}{P_{0}} R c\left(s_{1}\right) \leq R\left(\frac{\bar{B}}{P_{0}}+y_{0}\right)+\sum_{s_{1} \in S} \frac{q\left(s_{1}\right) P\left(s_{1}\right)}{P_{0}} R\left[y_{1}-T\left(s_{1}\right)\right]
$$


and the agent's problem can be restated as maximizing (1) subject to (15). Since $R>1$ our preference structure implies that no one consumes in period 0 :

$$
c_{0}^{h}=0, \quad \text { for all } h \in[0,1]
$$

Hence $\int_{0}^{1} k_{0}^{h} d h=y_{0}>0$ and thus there is storage in equilibrium. Define $h_{0}$ as

$$
h_{0}=\frac{q(U) P(U)}{P_{0}} R \text {. }
$$

It follows from (14) that $h_{0}$ is between 0 and 1 , and that

$$
1-h_{0}=\frac{q(D) P(D)}{P_{0}} R
$$

Then we see that $h_{0}$ is the marginal agent in the sense that agents $h>h_{0}$ make different choices than agents with $h<h_{0}$. Agents with $h>h_{0}$ are optimistic and choose $c^{h}(U)=0$. Agents with $h<h_{0}$ are pessimistic and choose $c^{h}(D)=0$.

Next consider the government. Equations (2) and (4) imply

$$
B_{0}=\frac{\bar{B}}{q_{0}}
$$

and it follows that the price level in period 1 is

$$
P\left(s_{1}\right)=\frac{1}{T\left(s_{1}\right)} \frac{\bar{B}}{q_{0}}, \quad s_{1} \in S .
$$

Using the no-arbitrage condition (13), we can combine the flow budget constraints (2)-(3) to derive the government's present value budget constraint

$$
\frac{\bar{B}}{P_{0}}=\sum_{s_{1} \in s} \frac{q\left(s_{1}\right)}{P_{0}} P\left(s_{1}\right) T\left(s_{1}\right)
$$

Then use (17) to write this expression as

$$
\frac{\bar{B}}{P_{0}}=h_{0} \frac{T_{H}}{R}+\left(1-h_{0}\right) \frac{T_{L}}{R} .
$$

Note that this equation determines $P_{0}$ given $h_{0}$.

Next we use the market clearing restrictions to determine the identity of the marginal agent. Starting with the agent's lifetime budget constraint (15) and using (20), its right hand side becomes

$$
R\left(\frac{\bar{B}}{P_{0}}+y_{0}\right)+\sum_{s_{1} \in S} \frac{q\left(s_{1}\right) P\left(s_{1}\right)}{P_{0}} R\left[y_{1}-T\left(s_{1}\right)\right]=R y_{0}+y_{1}
$$


Thus (15) can be rewritten as

$$
R c_{0}+h_{0} c(U)+\left(1-h_{0}\right) c(D) \leq R y_{0}+y_{1} .
$$

It follows that the consumption allocation is given by:

$$
\begin{aligned}
& c^{h}(U)= \begin{cases}\frac{1}{h_{0}}\left(R y_{0}+y_{1}\right), & \text { for } h>h_{0}, \\
0, & \text { for } h \leq h_{0},\end{cases} \\
& c^{h}(D)= \begin{cases}0, & \text { for } h>h_{0}, \\
\frac{1}{1-h_{0}}\left(R y_{0}+y_{1}\right), & \text { for } h \leq h_{0} .\end{cases}
\end{aligned}
$$

Market clearing implies

$$
R y_{0}+y_{1}=\int_{0}^{1} c^{h}(U) d h=\frac{1-h_{0}}{h_{0}}\left(R y_{0}+y_{1}\right),
$$

which yields the identity of the marginal agent

$$
h_{0}=\frac{1}{2} .
$$

Finally, the Arrow security prices $q\left(s_{1}\right)$ are determined by solving $\frac{q\left(s_{1}\right) P\left(s_{1}\right)}{P_{0}} R=\frac{1}{2}$ for each $s_{1} \in S$. The next proposition summarizes the result.

Proposition 1. In the two period model with complete asset markets, (i) the equilibrium consumption allocation $\left\{c_{0}^{h},\left[c^{h}\left(s_{1}\right)\right]_{s_{1} \in S}\right\}_{h \in[0,1]}$ is given by (16), (21), and (22), where the marginal agent $h_{0}=\frac{1}{2}$; and (ii) the equilibrium price levels $\left\{P_{0},\left[P\left(s_{1}\right)\right]_{s_{1} \in S}\right\}$ are given by (19) and (20).

One implication of this proposition is that the consumption allocation is independent of government policy or in other words Ricardian equivalence obtains. In the other two market structures we consider Ricardian equivalence fails.

\section{$3.2 \quad$ No borrowing}

Now suppose that Arrow securities are no longer traded, so that government bonds and storage are the only assets available to agents. It follows that these assets are no longer redundant. Since there are two assets (storage and government bonds) and two states $(U$ and $D)$ asset markets are still complete. However, we now rule out borrowing. Moreover, our previous assumption that short selling of government debt is prohibited is no longer innocuous. These financial frictions imply that the competitive equilibrium in this specification is not Pareto Optimal whereas the equilibrium considered in the previous subsection is Pareto Optimal. For these reasons we will refer to this new setup as the no-borrowing specification. 
Budget constraints for each agent are now given by

$$
\begin{aligned}
& c_{0}+k_{0}+q_{0} \frac{b_{0}}{P_{0}} \leq \frac{\bar{B}}{P_{0}}+y_{0}, \\
& c\left(s_{1}\right) \leq R k_{0}+\frac{b_{0}}{P\left(s_{1}\right)}+y_{1}-T\left(s_{1}\right), \quad s_{1} \in S, \\
& c_{0}, k_{0}, b_{0}, c\left(s_{1}\right) \geq 0, \quad s_{1} \in S .
\end{aligned}
$$

Each agent maximizes (1) subject to these constraints.

Definition 2 (No-borrowing Competitive Equilibrium). Given a government policy $\left(q_{0}, T_{H}\right.$, $T_{L}$ ), a no-borrowing competitive equilibrium consists of an allocation $\left\{c_{0}^{h},\left[c^{h}\left(s_{1}\right)\right]_{s_{1} \in S}, k_{0}^{h}\right.$, $\left.b_{0}^{h}\right\}_{h \in[0,1]}$, supply of government bonds $B_{0}$, and prices $\left\{P_{0},\left[P\left(s_{1}\right)\right]_{s_{1} \in S}\right\}$ such that (i) for each agent $h \in[0,1],\left\{c_{0}^{h},\left[c^{h}\left(s_{1}\right)\right]_{s_{1} \in S}, k_{0}^{h}, b_{0}^{h}\right\}$ solves her utility maximization problem; (ii) the government flow budget constraints $(2)-(3)$ are satisfied, where taxes $\left\{T_{0},\left[T\left(s_{1}\right)\right]_{s_{1} \in S}\right\}$ are given by (4)-(5); and (iii) all markets clear, i.e., equations (9)-(11) hold.

Consider the utility maximization problem of agent $h \in[0,1]$. Once again no agent will choose to consume in period 0: $c_{0}^{h}=0$ for all $h \in[0,1]$. Each agent will hold only the asset that offers her the highest expected return. Let $h_{0} \in[0,1]$ be the agent who is indifferent between government bonds and storage. We refer to this agent as the marginal buyer. The identity of $h_{0}$ is given by the solution to

$$
\frac{P_{0}}{q_{0}}\left\{\frac{1}{P(U)} h_{0}+\frac{1}{P(D)}\left(1-h_{0}\right)\right\}=R,
$$

where the left-hand side is the real rate of return on government bonds, and the right-hand side the real rate of return on storage. Agents with $h>h_{0}$ have optimistic beliefs about the return on government bonds and only hold government bonds. Agents with $h<h_{0}$, on the contrary, are pessimistic about the return on government bonds and hold no government bonds at all. Thus, the solution to the utility maximization problem can be summarized as follows:

$$
\begin{aligned}
& c_{0}^{h}=0, \quad h \in[0,1], \\
& k_{0}^{h}= \begin{cases}0, & h>h_{0}, \\
\frac{\bar{B}}{P_{0}}+y_{0}, & h \leq h_{0},\end{cases} \\
& b_{0}^{h}= \begin{cases}\frac{P_{0}}{q_{0}}\left(\frac{\bar{B}}{P_{0}}+y_{0}\right), & h>h_{0}, \\
0, & h \leq h_{0},\end{cases} \\
& c^{h}\left(s_{1}\right)= \begin{cases}\frac{1}{P\left(s_{1}\right)} \frac{P_{0}}{q_{0}}\left(\frac{\bar{B}}{P_{0}}+y_{0}\right)+y_{1}-T\left(s_{1}\right), & h>h_{0}, \\
R\left(\frac{\bar{B}}{P_{0}}+y_{0}\right)+y_{1}-T\left(s_{1}\right), & h \leq h_{0} .\end{cases}
\end{aligned}
$$


As in the previous case, $B_{0}=\bar{B} / q_{0}$, and hence the price level in state $s_{1}, P\left(s_{1}\right)$, is determined by (19). From (29) it follows that the market clearing condition for government bonds is

$$
\frac{q_{0}}{P_{0}} B_{0}=\left(1-h_{0}\right)\left(\frac{\bar{B}}{P_{0}}+y_{0}\right)
$$

which implies that the price level in period $0, P_{0}$, is given by

$$
P_{0}=\frac{h_{0}}{1-h_{0}} \frac{\bar{B}}{y_{0}}
$$

The next proposition summarizes these results.

Proposition 2. The two period no-borrowing equilibrium has the following properties: (i) the equilibrium consumption allocation/portfolio, $\left\{c_{0}^{h}, k_{0}^{h}, b_{0}^{h},\left[c^{h}\left(s_{1}\right)\right]_{s_{1} \in S}\right\}_{h \in[0,1]}$, is given by (27)(30); (ii) the identity of the marginal buyer of government bonds, $h_{0}$, is given by (26); and (iii) the equilibrium price levels $\left\{P_{0},\left[P\left(s_{1}\right)\right]_{s_{1} \in S}\right\}$ are given by (19) and (31).

\subsection{Leveraged purchases of government bonds}

We now consider a market structure where agents can borrow and lend to each other. Short sales of government debt though are still prohibited. We refer to this specification as the leverage specification. The leverage competitive equilibrium is also not Pareto Optimal but produces different allocations from the no-borrowing specification.

In this market structure optimistic agents, who believe that the rate of return on government bonds is greater than the borrowing rate, want to borrow as much as possible and purchase government bonds. Assume further that a borrower is required to post government bonds as collateral in order to obtain a loan. How much can an agent borrow with one unit of government bonds as collateral? One way to proceed would be to impose an exogenous ad hoc constraint as in e.g. Kiyotaki and Moore (1997). We pursue an alternative avenue that allows us to determine the collateral constraint endogenously. Geanakoplos (2003, 2010) allows for a broad array of loan/default schemes and determines which ones trade in equilibrium. In our setting this can be summarized by a "no-default constraint," that requires that the amount of repayments not exceed the value of the collateral in any state. We derive this result in the Appendix and directly impose the no-default constraint here.

Since there is no default on loans, loans are risk-free. Thus the interest rate on loans is equal to $R$ in equilibrium (as long as the storage technology is used). Consider an agent who borrows $\phi_{0}$ and purchases government bonds $b_{0}$ in period 0 . She must repay $R \phi_{0}$ in period 1. The no-default constraint requires that $R \phi_{0} \leq \frac{b_{0}}{P\left(s_{1}\right)}$, for all $s_{1} \in S$. Thus the budget 
constraints for each agents become

$$
\begin{aligned}
& c_{0}+k_{0}+q_{0} \frac{b_{0}}{P_{0}} \leq \frac{\bar{B}}{P_{0}}+y_{0}+\phi_{0}, \\
& c\left(s_{1}\right) \leq R k_{0}+\frac{b_{0}}{P\left(s_{1}\right)}+y_{1}-T\left(s_{1}\right)-R \phi_{0}, \quad s_{1} \in S, \\
& R \phi_{0} \leq \frac{b_{0}}{P\left(s_{1}\right)}, \quad s_{1} \in S \\
& c_{0}, k_{0}, b_{0}, c\left(s_{1}\right) \geq 0, \quad s_{1} \in S .
\end{aligned}
$$

Definition 3 (Leverage Competitive Equilibrium). Given a government policy $\left(q_{0}, T_{H}, T_{L}\right)$, a leverage competitive equilibrium consists of an allocation $\left\{c_{0}^{h},\left[c^{h}\left(s_{1}\right)\right]_{s_{1} \in S}, k_{0}^{h}, b_{0}^{h}, \phi_{0}^{h}\right\}_{h \in[0,1]}$, supply of government bonds $B_{0}$, and prices $\left\{P_{0},\left[P\left(s_{1}\right)\right]_{s_{1} \in S}\right\}$ such that (i) for each agent $h \in[0,1],\left\{c_{0}^{h},\left[c^{h}\left(s_{1}\right)\right]_{s_{1} \in S}, k_{0}^{h}, b_{0}^{h}, \phi_{0}^{h}\right\}$ solves her utility maximization problem; (ii) the government flow budget constraints $(2)-(3)$ are satisfied, where taxes $\left\{T_{0},\left[T\left(s_{1}\right)\right]_{s_{1} \in S}\right\}$ are given by (4)-(5); and (iii) all markets clear, i.e., equations (9)-(11) hold and $\int_{0}^{1} \phi_{0}^{h} d h=0$.

To characterize this equilibrium start with the utility maximization problem. No one consumes in period 0: $c_{0}^{h}=0$ for all $h \in[0,1]$. Observe that $P(U)<P(D)$ in equilibrium and thus the collateral constraint (34) can be expressed as $\phi_{0} \leq \frac{b_{0}}{R P(D)}$. In this setting there will be a marginal purchaser $h_{0}$ who is indifferent between storage and borrowing and using the proceeds to purchase government debt. This indifference relationship is given by

$$
h_{0} \frac{\frac{1}{P(U)}-\frac{1}{P(D)}}{\frac{q_{0}}{P_{0}}-\frac{1}{R P(D)}}=R
$$

and is identical to (26). Optimistic agents $h>h_{0}$ want to borrow as much as possible to purchase government bonds. On the other hand, pessimistic agents $h<h_{0}$ do not want to hold government bonds. However, they are perfectly willing to lend to optimistic agents at the interest rate $R$. Thus there will be leverage in equilibrium.

Given these results the solution to the utility maximization problem is summarized by:

$$
\begin{aligned}
& c_{0}^{h}=0, \quad h \in[0,1], \\
& b_{0}^{h}= \begin{cases}\left(\frac{q_{0}}{P_{0}}-\frac{1}{R P(D)}\right)^{-1}\left(\frac{\bar{B}}{P_{0}}+y_{0}\right), & h>h_{0}, \\
0, & h \leq h_{0},\end{cases} \\
& k_{0}^{h}-\phi_{0}^{h}= \begin{cases}-\frac{1}{R P(D)}\left(\frac{q_{0}}{P_{0}}-\frac{1}{R P(D)}\right)^{-1}\left(\frac{\bar{B}}{P_{0}}+y_{0}\right), & h>h_{0}, \\
\frac{\bar{B}}{P_{0}}+y_{0}, & h \leq h_{0},\end{cases} \\
& c^{h}\left(s_{1}\right)= \begin{cases}\frac{\frac{1}{P\left(s_{1}\right)}-\frac{1}{P(D)}}{\frac{q_{0}}{P_{0}}-\frac{1}{R P(D)}}\left(\frac{\bar{B}}{P_{0}}+y_{0}\right)+y_{1}-T\left(s_{1}\right), & h>h_{0}, \\
R\left(\frac{\bar{B}}{P_{0}}+y_{0}\right)+y_{1}-T\left(s_{1}\right), & h \leq h_{0} .\end{cases}
\end{aligned}
$$


Since storage and lending are perfect substitutes, only $k_{0}^{h}-\phi_{0}^{h}$ is determined for agents with $h \leq h_{0}$. Agents with $h>h_{0}$ set storage to zero, $k_{0}^{h}=0$, and borrow as much as they can:

$\phi_{0}^{h}=\frac{b_{0}^{h}}{R P(D)}$. As before, $B_{0}$ and $P\left(s_{1}\right), s_{1} \in S$, are determined by (18) and (19). Then it follows from (38) that the market clearing condition for government bonds is expressed as

$$
\frac{\bar{B}}{q_{0}}=\left(1-h_{0}\right)\left(\frac{q_{0}}{P_{0}}-\frac{1}{R P(D)}\right)^{-1}\left(\frac{\bar{B}}{P_{0}}+y_{0}\right) .
$$

Given $P\left(s_{1}\right), s_{1} \in S$, the initial price level $P_{0}$ and the marginal agent $h_{0}$ are determined as the solution to (36) and (41). The following proposition summarizes these results.

Proposition 3. In the two period leverage equilibrium, (i) the equilibrium consumption allocation/portfolio, $\left\{c_{0}^{h}, k_{0}^{h}-\phi_{0}^{h}, b_{0}^{h},\left[c^{h}\left(s_{1}\right)\right]_{s_{1} \in S}\right\}_{h \in[0,1]}$, is given by (37)-(40); (ii) the marginal buyer of government bonds, $h_{0}$, is given by (36); and (iii) the equilibrium price levels $\left\{P_{0}\right.$, $\left.\left[P\left(s_{1}\right)\right]_{s_{1} \in S}\right\}$ are given by (19) and (41).

\subsection{Numerical example}

We now turn to consider a particular thought exercise that is aimed to help us understand how the inflation rate evolves in each of these specifications when agents begin to expect that there is a possibility of a debt crisis.

We set the parameter values as $\bar{B}=1, y_{0}=y_{1}=1, q_{0}=1, R=1.02, T_{H}=R^{2}$, and $T_{L}=T_{H} / 2$. The choice of a gross nominal interest rate of one is chosen to reflect the current situation in Japan and the United States.

Suppose that in all periods prior to period zero the gross nominal interest rate is one and everyone believes that $s_{1}=U$ with probability one. That is, prior to period 0 , no one believes that a debt crisis will occur. Under these assumptions it follows that $P_{-1}=1$. Since $q_{-1}=1$ the inflation rate in period -1 is given by $\pi_{-1}=q_{-1} / R-1=-1.96$ percent. Suppose next that in period zero agents become worried that a debt crisis may occur in period one and that they have different degrees of confidence about this possibility.

Table 1 shows the inflation rate at $t=-1, t=0$ and at $s_{1}=D$ for the "complete markets," "no borrowing," and "leverage" specifications, respectively. The inflation rate in period zero, $\pi_{0}$, is highest in the model with complete markets and lowest in the model with leverage. This ranking is reversed in period one if state $D$ is realized and the debt crisis occurs. $\pi(D)$ is highest with leverage and lowest with complete markets.

In the complete markets specification when the news about a future crisis arrives in period zero these beliefs are instantly reflected in the price level and the inflation rate jumps up to a value of 30.72 percent. The inflation rate also jumps up in the leverage specification. But 
the size of the jump in period zero is much smaller as compared to the complete markets specification. Instead there is a much larger jump in the inflation rate in the state where the debt crisis occurs.

There is simple intuition behind this result. In the model with complete markets, every agent can freely bet on her beliefs: optimistic agents buy the Arrow security $U$ and sell Arrow security $D$, and pessimistic agents do the opposite. A unique feature of the complete markets specification is that by betting against the perceived low probability state agents can commit to deliver their future endowment if that state occurs. In the other two specifications they cannot make this promise. In the no-borrowing equilibrium agents can only choose how to save in the form of bonds or storage. In the leverage equilibrium optimistic agents can also undertake collateralized borrowing which makes it possible for them to promise to deliver the return on government bonds in period one and thereby mimic a purchase of Arrow security $U$. However, they are not able to mimic a sale of Arrow security $D$. For pessimistic agents the problem is more severe as there is no way for them to mimic either selling the Arrow security $U$ or purchasing the Arrow security $D$.

The inability of agents to promise their period 1 endowment results in a higher value of $h_{0}$ in the no-borrowing and leverage specifications. This translates into a lower inflation rate $\pi_{0}$ compared to the case with complete markets. The asymmetry between optimists and pessimists in the leverage specification enhances these effects and that specification delivers the lowest inflation rate in period zero.

\section{T-period model}

In this section we shall see that the effect of the asset market structure on the dynamics of the inflation rate becomes more apparent when the time horizon is extended.

Suppose that there are $T+1$ periods indexed by $t=0,1, \ldots, T$. In each period $t=1, \ldots, T$, a shock $s_{t} \in S=\{U, D\}$ is realized. For $t=1, \ldots, T$, let $s^{t}=\left(s_{1}, \ldots, s_{t}\right) \in S^{t}$ denote the history of shocks, and also let $s^{0} \equiv 0$ and $S^{0} \equiv\{0\}$. In each period $t$, regardless of the history $s^{t}$, agent $h$ believes that $s_{t+1}=U$ with probability $h$ and $s_{t+1}=D$ with probability $1-h$. Then her expected utility is expressed as

$$
\sum_{t=0}^{T} \sum_{s^{t} \in S^{t}} \gamma^{h}\left(s^{t}\right) c\left(s^{t}\right),
$$

where $\gamma^{h}\left(s^{t}\right)$ denotes the subjective probability that agent $h$ assigns to history $s^{t}$ in period 0 . 
That is,

$$
\gamma^{h}\left(s^{t}\right)= \begin{cases}h \gamma^{h}\left(s^{t-1}\right), & \text { if } s_{t}=U \\ (1-h) \gamma^{h}\left(s^{t-1}\right), & \text { if } s_{t}=D\end{cases}
$$

with $\gamma^{h}\left(s^{0}\right) \equiv 1$.

In each period $t$, all agents are endowed with equal amounts of the consumption good, $y\left(s^{t}\right)$ for $s^{t} \in S^{t}$. For simplicity, we assume that

$$
y\left(s^{t}\right)= \begin{cases}y_{0}, & \text { for } t=0 \\ 0, & \text { for all } s^{t} \text { with } t=1, \ldots, T-1, \\ y_{T}, & \text { for all } s^{T}\end{cases}
$$

In addition, at the beginning of period 0, all agents are endowed with equal amounts of government debt $\bar{B}>0$.

As in the two-period model, the government specifies a fiscal policy which consists of a state-contingent path of lump-sum taxes $\left\{T\left(s^{t}\right): s^{t} \in S^{t}, t=0, \ldots, T\right\}$. To be specific, fiscal policy takes the following form:

$$
T\left(s^{t}\right)= \begin{cases}0, & \text { for all } s^{t} \text { with } t=0, \ldots, T-1, \\ T_{L}, & \text { for } s^{T}=D^{T} \\ T_{H}, & \text { for all } s^{T} \neq D^{T}\end{cases}
$$

The government also chooses a monetary policy which is a state-contingent path of the price of government bonds, $\left\{q\left(s^{t}\right): s^{t} \in S^{t}, t=0, \ldots, T\right\}$. Given these government policies, the government debt $B\left(s^{t}\right)$ evolves as

$$
\begin{aligned}
\bar{B} & =q_{0} B_{0}, \\
B\left(s^{t-1}\right) & =q\left(s^{t}\right) B\left(s^{t}\right), \quad s^{t} \in S^{t}, t=1, \ldots, T-1, \\
B\left(s^{T-1}\right) & =P\left(s^{T}\right) T\left(s^{T}\right), \quad s^{T} \in S^{T} .
\end{aligned}
$$

Figure 2 illustrates the implications of these assumptions using an event tree for the special case where $T=2$. A debt crisis only occurs when the government collects $T_{L}$ taxes in the final period. Under our assumption (43), it occurs only if $s_{t}=D$ for all $t=1, \ldots, T$. In the case of $T=2$ illustrated in the figure this corresponds to the bottom outcome where the history is $\{D, D\}$. In the other three histories in the last period there is no crisis. For general $T$ there will only be one history in the final period that produces a crisis. From this it follows that extending the horizon acts to lower the perceived probability of a crisis. 


\subsection{Complete markets}

Let $q\left(s_{t+1} \mid s^{t}\right)$ denote the price of the Arrow security traded at $s^{t}$ that pays off one unit of account if and only if $s_{t+1}$ occurs in the next period. With a complete set of Arrow securities, the flow budget constraints for each agent are given by

$$
\begin{aligned}
& c_{0}+k_{0}+\sum_{s_{1} \in S} q\left(s_{1} \mid s^{0}\right) \frac{b\left(s_{1} \mid s^{0}\right)}{P_{0}}+q_{0} \frac{b_{0}}{P_{0}} \leq \frac{\bar{B}}{P_{0}}+y_{0}, \\
& c\left(s^{t}\right)+k\left(s^{t}\right)+\sum_{s_{t+1} \in S} q\left(s_{t+1} \mid s^{t}\right) \frac{b\left(s_{t+1} \mid s^{t}\right)}{P\left(s^{t}\right)}+q\left(s^{t}\right) \frac{b\left(s^{t}\right)}{P\left(s^{t}\right)} \\
& \leq \frac{b\left(s_{t} \mid s^{t-1}\right)}{P\left(s^{t}\right)}+\frac{b\left(s^{t-1}\right)}{P\left(s^{t}\right)}+R k\left(s^{t-1}\right), \quad t=1, \ldots, T-1, s^{t} \in S^{t}, \\
& c\left(s^{T}\right) \leq \frac{b\left(s_{T} \mid s^{T-1}\right)}{P\left(s^{T}\right)}+\frac{b\left(s^{T-1}\right)}{P\left(s^{T}\right)}+R k\left(s^{T-1}\right)+y_{T}-T\left(s^{T}\right), \quad s^{T} \in S^{T}, \\
& c\left(s^{t}\right), k\left(s^{t}\right), b\left(s^{t}\right) \geq 0, \quad s^{t} \in S^{t}, t=0, \ldots, T,
\end{aligned}
$$

where $b\left(s_{t+1} \mid s^{t}\right)$ denotes the quantities of the Arrow securities purchased at $s^{t}$, and $b\left(s^{t}\right)$ denotes the quantities of government bonds purchased at $s^{t}$.

Given a policy $\left(\left\{q\left(s^{t}\right)\right\}, T_{H}, T_{L}\right)$, a competitive equilibrium is defined as in the two-period case.

It is also interesting to understand how the identity of the marginal buyer evolves along the path that results in a crisis. It can be shown that her identity evolves according to the following rule:

$$
h\left(D^{t}\right)=\frac{1}{t+2}, \quad t=1,2, \ldots, T,
$$

with $h_{0}=1 / 2$. A proof of this result can be found in the Appendix. 


\subsection{Leveraged purchases of government bonds}

Now suppose that Arrow securities are no longer traded, and borrowing is limited by the no-default condition. The flow budget constraints for agents are

$$
\begin{aligned}
& c_{0}+k_{0}+q_{0} \frac{b_{0}}{P_{0}} \leq \frac{\bar{B}}{P_{0}}+y_{0}+\phi_{0}, \\
& c\left(s^{t}\right)+k\left(s^{t}\right)+q\left(s^{t}\right) \frac{b\left(s^{t}\right)}{P\left(s^{t}\right)} \\
& \leq \frac{b\left(s^{t-1}\right)}{P\left(s^{t}\right)}+R k\left(s^{t-1}\right)-R \phi\left(s^{t-1}\right)+\phi\left(s^{t}\right), \quad t=1, \ldots, T-1, s^{t} \in S^{t}, \\
& c\left(s^{T}\right) \leq \frac{b\left(s^{T-1}\right)}{P\left(s^{T}\right)}+R k\left(s^{T-1}\right)+y_{T}-T\left(s^{T}\right)-R \phi\left(s^{T-1}\right), \quad s^{T} \in S^{T}, \\
& R \phi\left(s^{t}\right) \leq \frac{b\left(s^{t}\right)}{P\left(s^{t}, s_{t+1}\right)}, \quad t=0, \ldots, T-1, s^{t} \in S^{t}, s_{t+1} \in S, \\
& c\left(s^{t}\right), k\left(s^{t}\right), b\left(s^{t}\right) \geq 0, \quad s^{t} \in S^{t}, t=0, \ldots, T,
\end{aligned}
$$

\subsection{Two additional numerical examples}

We now consider two further numerical examples that illustrate how the properties of the model change when the time horizon is extended. In the first example all uncertainty is resolved at the end of period two. In the second example the economy ends at the end of period five.

We consider the same parameterization of the model as before. Let $\bar{B}=1, y_{0}=y_{T}=1$, $q\left(s^{t}\right)=1$ for all $s^{t}$ and $t, R=1.02, T_{H}=R^{T+1}$, and $T_{L}=T_{H} / 2$. Also, assume that in period -1, everyone believes that $\operatorname{Pr}\left(s^{T}=D^{T}\right)=0$, that is, everyone believes that the government collects taxes of amount $T_{H}$ in period $T$ for sure. It follows that $P_{-1}=1$. Recall also that $\pi_{-1}=-1.96$ percent.

Table 2 contains results for the three period model. The first two columns report $\pi_{-1}$, the inflation rate in period -1 , and $\pi_{0}$, the inflation rate in period zero. Columns three and four report the inflation rate in particular states. Column three reports its value in period one when the realization is $D$ and column four reports the value of the inflation rate in period two when the realization is $\{D, D\}$. The final two columns of this table report the identity of the marginal purchaser in period zero and in period one when the state is $D$.

Consider first the results for complete markets. For this parameterization of the model the inflation rate jumps from -1.96 percent to 17.65 percent in period zero when individuals realize that there is a possibility of a debt crisis. As compared to Table 1, the size of the jump in the inflation rate in period zero is now smaller. For all agents the possibility of a fiscal crisis is lower when the model has three periods. It is now $(1-h)^{2}$ as compared to 
$(1-h)$ before. The size of the jump in period zero at 17.65 percent is still very large. Notice also that the jump if the crisis state is realized in the final period, $\pi\left(D^{2}\right)$, is smaller when the horizon is extended by one period. Extending the horizon tends to smooth out the inflation response in the complete markets specification.

It is also interesting to consider the dynamics of the marginal buyer. In the two period model the marginal buyer is $h_{0}=1 / 2$ or the midpoint of the interval. This continues to be the case in the three period model. In period 1 when the state $D$ is realized the net worth of the optimistic individuals with $h>h_{0}$ falls to zero. The remaining individuals with positive net worth enter into new agreements and it follows from equation (51) that the new marginal purchaser is $h(D)=1 / 3$.

Observe next that the properties of the model are very different when we use the market structure with leverage. The size of the inflation rate response is now very small (-1.09 percent) when the news arrives in period zero. For purposes of comparison, in the two period model inflation increased to 9.46 percent in period zero. This response is also qualitatively quite different from the complete markets specification. In the specification with leverage there is still deflation immediately after the news arrives whereas with complete markets the inflation rate is very large and positive. A further distinction between the two period and three period model is that the inflation rate is now slightly lower in the final period. In the two period model it is 75.62 percent in the final period in the three period model it falls to 71.89 percent. However, the gap between the inflation rate in the final period and the inflation rate in period zero is now larger.

A further important distinction between the two market structures relates to the dynamics of the marginal buyer. For complete markets we know from (51) that the marginal buyer in period zero is always $h_{0}=1 / 2$ regardless of the number of periods in the model. In the leverage specification the opposite is the case. The identity of the marginal buyer in period zero increases as the number of periods in the model is increased. Suppose next that we follow the path leading to the crisis state and consider the period prior to the crisis. Along this leg of the event tree we see that the identity of the marginal buyer in the three period model, 0.75, is quite close to the identity of the marginal buyer in the two period model, 0.79 .

Taken together these results suggest that increasing the horizon acts to reduce the impact response of inflation at the time news arrives about the possibility of a future crisis and concentrate its response in the crisis state.

To make this point more transparent we report results for the model with a six period planning horizon in Figure 3. Figure 3 plots the inflation rate for the complete markets specification and the leverage specification. Observe that for the complete markets specification 
the smoothing property is more pronounced. The inflation rate now jumps to 7 percent in period zero and then rises slowly but steadily to a maximum of about 14 percent.

The concentration of inflation in the crisis state that occurs in the leverage specification is much more pronounced in the six period model. In fact, there is no longer a discernible jump in the inflation rate in period zero. ${ }^{5}$ We previously saw in the three period model that the inflation rate turned positive in period 1 . Here we can see very clearly that increasing the horizon acts to delay the response of the inflation rate. In period 3 , for instance, the inflation rate is still very low at -1.01 percent. It is only in period four that we see a substantial increase in the inflation rate to 10.97 percent. The biggest increase is concentrated in the final period when the crisis state is realized (71.57 percent). This is very close to the value of the inflation rate in the crisis state in the three period model (71.89 percent).

This fact can be related to the identity of the marginal buyer in the period before the crisis. For the three period model her identify was (about) 0.75. Interestingly, her identity is also about 0.75 in the six period model. This is why the final period inflation rate is very similar in the two simulations.

\section{$5 \quad$ Explicit default}

We now turn to consider a setting with explicit default and long-term debt. We will assume that this is the only way default can occur. In particular, price levels $\left\{P\left(s^{t}\right)\right\}$ are now given exogenously and thus the price level is no longer determined by fiscal policy. These assumptions are designed to reflect the situation of a small country (or state) that is a member of a currency union.

Let $\bar{B}$ be the face value of government debt in period 0 and suppose that it does not issue any new debt in any other period. All government debt is long-term and matures in the last period, T. Moreover, suppose that the government only collects taxes in the last period. Under these assumptions the nominal outstanding value of government debt is $\bar{B}$ in all but the last period.

As before, a shock $s_{t} \in\{U, D\}$ is realized in each period $t$. The government defaults in period $T$ only if $s^{T}=D^{T}$; it repays the full amount of $\bar{B}$ otherwise. When the government defaults, it repays only a fraction $\alpha \in(0,1)$ of $\bar{B}$. It follows that the amount of taxes collected

\footnotetext{
${ }^{5}$ Using Matlab the increase in the size of the inflation rate between period -1 and zero is 2e-014 which is close to the limits of machine precision.
} 
in the last period, $T\left(s^{T}\right)$, is given by

$$
T\left(s^{T}\right)=\alpha\left(s^{T}\right) \frac{\bar{B}}{P\left(s^{T}\right)},
$$

where $\alpha\left(s^{T}\right)$ is defined as

$$
\alpha\left(s^{T}\right)= \begin{cases}\alpha, & \text { if } s^{T}=D^{T} \\ 1, & \text { otherwise }\end{cases}
$$

In the complete markets specification, the flow budget constraints for each agent are given by

$$
\begin{aligned}
& c_{0}+k_{0}+\sum_{s_{1} \in S} q\left(s_{1} \mid s^{0}\right) \frac{b\left(s_{1} \mid s^{0}\right)}{P_{0}}+q_{0} \frac{b_{0}}{P_{0}} \leq q_{0} \frac{\bar{B}}{P_{0}}+y_{0}, \\
& c\left(s^{t}\right)+k\left(s^{t}\right)+\sum_{s_{t+1} \in S} q\left(s_{t+1} \mid s^{t}\right) \frac{b\left(s_{t+1} \mid s^{t}\right)}{P\left(s^{t}\right)}+q\left(s^{t}\right) \frac{b\left(s^{t}\right)}{P\left(s^{t}\right)} \\
& \leq \frac{b\left(s_{t} \mid s^{t-1}\right)}{P\left(s^{t}\right)}+q\left(s^{t}\right) \frac{b\left(s^{t-1}\right)}{P\left(s^{t}\right)}+R k\left(s^{t-1}\right), \quad t=1, \ldots, T-1, s^{t} \in S^{t}, \\
& c\left(s^{T}\right) \leq \frac{b\left(s_{T} \mid s^{T-1}\right)}{P\left(s^{T}\right)}+\alpha\left(s^{T}\right) \frac{b\left(s^{T-1}\right)}{P\left(s^{T}\right)}+R k\left(s^{T-1}\right)+y_{T}-T\left(s^{T}\right), \quad s^{T} \in S^{T}, \\
& c\left(s^{t}\right), k\left(s^{t}\right), b\left(s^{t}\right) \geq 0, \quad s^{t} \in S^{t}, t=0, \ldots, T,
\end{aligned}
$$

The market clearing condition is

$$
\begin{aligned}
\int_{0}^{1} b^{h}\left(s^{t}\right) d h & =\bar{B}, \quad \text { for all } s^{t} \in S^{t} \text { and } t=0, \ldots, T-1, \\
\int_{0}^{1} b^{h}\left(s_{t+1} \mid s^{t}\right) d h & =0, \quad \text { for all } s^{t} \in S^{t}, s_{t+1} \in S, \text { and } t=0, \ldots, T-1, \\
\int_{0}^{1}\left(c_{0}^{h}+k_{0}^{h}\right) d h & =y_{0}, \\
\int_{0}^{1}\left(c^{h}\left(s^{t}\right)+k^{h}\left(s^{t}\right)\right) d h & =\int_{0}^{1} R k^{h}\left(s^{t-1}\right) d h, \quad \text { for all } s^{t} \in S^{t} \text { and } t=0, \ldots, T-1, \\
\int_{0}^{1} c^{h}\left(s^{T}\right) d h & =y_{T}+\int_{0}^{1} R k^{h}\left(s^{T-1}\right) d h, \quad \text { for all } s^{T} \in S^{T} .
\end{aligned}
$$


In the leverage specification, the flow budget constraints are given by

$$
\begin{aligned}
& c_{0}+k_{0}+q_{0} \frac{b_{0}}{P_{0}} \leq q_{0} \frac{\bar{B}}{P_{0}}+y_{0}+\phi_{0}, \\
& c\left(s^{t}\right)+k\left(s^{t}\right)+q\left(s^{t}\right) \frac{b\left(s^{t}\right)}{P\left(s^{t}\right)} \\
& \leq q\left(s^{t}\right) \frac{b\left(s^{t-1}\right)}{P\left(s^{t}\right)}+R k\left(s^{t-1}\right)-R \phi\left(s^{t-1}\right)+\phi\left(s^{t}\right), \quad t=1, \ldots, T-1, s^{t} \in S^{t}, \\
& c\left(s^{T}\right) \leq \alpha\left(s^{T}\right) \frac{b\left(s^{T-1}\right)}{P\left(s^{T}\right)}+R k\left(s^{T-1}\right)+y_{T}-T\left(s^{T}\right)-R \phi\left(s^{T-1}\right), \quad s^{T} \in S^{T}, \\
& R \phi\left(s^{t}\right) \leq q\left(s^{t}, s_{t+1}\right) \frac{b\left(s^{t}\right)}{P\left(s^{t}, s_{t+1}\right)}, \quad t=0, \ldots, T-2, s^{t} \in S^{t}, s_{t+1} \in S, \\
& R \phi\left(s^{T-1}\right) \leq \alpha\left(s^{T-1}, s_{T}\right) \frac{b\left(s^{T-1}\right)}{P\left(s^{T-1}, s_{T}\right)}, \quad s^{T-1} \in S^{T-1}, s_{T} \in S, \\
& c\left(s^{t}\right), k\left(s^{t}\right), b\left(s^{t}\right) \geq 0, \quad s^{t} \in S^{t}, t=0, \ldots, T \text {. }
\end{aligned}
$$

The market clearing conditions have a similar form to before.

Suppose that the nominal interest rate in the world is constant and given by $1 / \bar{q}$. It follows that the price level evolves as $P_{t+1} / P_{t}=1 /(R \bar{q})$. In the following numerical example, we set $\bar{q}=R=1.02 ; y_{0}=y_{T}=\bar{B}=1 ; \alpha=0.2$. Let $\rho\left(D^{t}\right)$ denote the log yield of the government debt in state $D^{t}$ for each period $t$. That is,

$$
\rho\left(D^{t}\right) \equiv-\frac{1}{T-t} \ln \left[q\left(D^{t}\right)\right], \quad t=0, \ldots, T-1 .
$$

As before, we assume that prior to period 0, everyone believes that the probability of the government defaulting is zero, that is, $\alpha\left(s^{T}\right)=1$ for all $s^{T}$. It follows that the log yield in period $t=-1, \rho_{-1}$, is equal to $-\ln (\bar{q})$.

Table 3 reports results for the complete markets and the leverage specifications for the case where $T=4$. Consider the complete markets specification first. When the news arrives in period zero the prospect of a future default on the long-term bond produces a jump in its yield from 1.98 percent to 6.34 percent. As before the marginal buyer $h_{0}=1 / 2$. Along the path towards default $h\left(D^{t}\right)$ falls in exactly the same way as before, at the rate $1 /(t+2)$. Along the path to default optimistic agents from the previous period get wiped out when the $D$ event is realized. They have zero wealth and are inactive in subsequent periods along this path. The result is that $h\left(D^{t}\right)$ falls quickly. A lower value of $h\left(D^{t}\right)$ implies successively lower prices on government debt or alternatively higher yields.

In the leverage specification there is once again a delayed response. In period zero $h_{0}$ is virtually one and the yield on the long term bond does not respond to the news. Along the path leading to default optimistic individuals experience a gradual tightening in the amount 
that they can borrow as the price of the long-term bond increases. However, optimistic agents continue to be active and the declines in $h\left(D^{t}\right)$ are much smaller here as compared to the complete markets case. This results in a higher price (lower yield) on the long term bond in all periods along this path relative to the complete markets benchmark.

\section{Discussion}

The results we have presented are based on a very stark model that is designed to capture the essential features of the world we are attempting to model. We believe though that these results also apply in more general and complex environments. We now turn to discuss the robustness of our findings to some of our principal assumptions.

The single most important assumption driving our results is the restriction on short sales of government debt. It is well known that some institutional investors take short positions on sovereign debt. However, the data presented in Table 4 indicates that the financial sector as a whole has a very large long position in government debt in both the U.S. and Japan.

Table 4 provides data on ownership of government debt in these two countries. In the U.S., financial institutions hold 68 percent of total outstanding privately held debt. ${ }^{6}$ In Japan the ratio is even higher. Almost 84 percent of privately held debt is held by financial institutions.

Another piece of evidence that suggests that financial frictions on short sales of government debt are significant is the gap on mortgage and government bond rates. If it was cheap to short sovereign debt this would be a much cheaper way to finance a mortgage. Table 5 reports spreads of government bond yields and mortgage rates for the U.S. and Japan at alternative maturities. U.S. spreads range from a high of 2.84 percent to 0.51 percent. In Japan they range from 1.22 percent to 0.46 percent. Loan origination costs increase the gap even further.

Finally it is not unusual for governments to introduce a state dependent form of restriction on short sales that make it more difficult to short government debt in states of nature where the risk of default is elevated. For instance, in August of 2011 as risk premia on their sovereign debt shot up governments in Belgium, France, Italy and Spain all imposed bans on short sales. According to the results in Section 5 these actions are an effective way to lower yields. In our current model though they have no implications for the probability of default.

A second issue relates to the specific motives of why particular individuals/sectors take long leveraged positions in government debt when the risk of a crisis increases. The model relies on heterogeneous beliefs to generate differences in demand for government debt. Our

\footnotetext{
${ }^{6}$ Our definition of privately held is based on the depositor. Thus we classify public pension plans and central bank holdings as part of privately held debt.
} 
results would also go through if these differences in demand were produced by alternative differences in preferences such as differences in risk aversion. Government debt is risky and safe storage is not. With differences in risk aversion less risk averse individuals will borrow from the high risk averse types to purchase more government debt.

In the real world leveraged purchases of government debt are central to financial intermediation. To see why this is the case consider the following strategy that optimistic individuals undertake in our economy: borrow from pessimistic individuals and use these resources to purchase government debt. In the real world this is a central role of the financial services sector: it accepts deposits and purchases government debt. Institutional restrictions such as capital requirements provide specific incentives for banks to behave in this way. If a bank uses any new deposits it receives to purchase government bonds, this increases tier one capital and thereby helps a bank to meet its capital requirements. Another institutional constraint applies to public pension plans which are required to take long leveraged positions on government debt.

We have assumed in the numerical examples that $q\left(s^{t}\right)=1$ for all $s^{t}$ or that the nominal interest rate is zero in all histories. That assumption was made to capture the current situations of Japan and the U.S. However, this assumption is not essential to our results. Our results would also go through though if $1 / q>1$. Setting $1 / q>1$ would just scale up the inflation rate.

\section{Conclusion}

In this paper we have described the evolution of inflation in an economy that faces a surprise increase in the risk of a sovereign debt crisis. A debt crisis is a situation where taxes remain low and the government budget constraint can only be satisfied by a large increase in the price level which deflates the real value of government liabilities. We have found that if markets are complete the inflation rate jumps on the date that the risk of a crisis is perceived to increase and remains high. We also described an alternative market structure with short sale restrictions. Our principal result is that under this alternative there is no discernible impact response of the inflation rate to an increase in the risk of default. Inflationary pressure can remain low for many periods and becomes concentrated in the states of nature where the crisis occurs. In short, the message of our paper is that the fact that the inflation rate is low today does not mean that the risk of a future crisis is low.

We also considered a setting with long-term government debt and explicit default. Our results suggest that actions by governments to rule out short selling of government debt are, 
in principal, an effective way to reduce the response of prices. However, in our model the default event is not effected by these actions. In our future work we plan to consider settings where the probability of default is endogenous such as in Bi (2011) or Davig, Leeper and Walker (2011).

\section{Appendix}

\subsection{Equilibrium level of leverage}

Here we follow Geanakoplos $(2003,2010)$ and discuss how the equilibrium level of leverage is determined in our model. Consider the two period model in which a variety of loans are traded in period zero. The unit of each loan is normalized so that one unit of each loan requires one unit of collateral (government debt). One unit of type $j$ loan is a promise to pay $j$ units of goods in period one. All loans are assumed to be non-recourse. It follows that the actual repayment made in period one by an agent who obtains a unit of type $j$ loan repays in period zero is $\left\{j, 1 / P\left(s_{1}\right)\right\}$ for each $s_{1} \in S$. Let $J$ denote the set of loans traded in period 0 , which is assumed to be finite. We assume that

$$
j^{*} \equiv 1 / P(D) \in J
$$

Note that the loan of type $j^{*}$ corresponds to the loan considered in the main text. Here we show that only loans of type $j^{*}$ are traded in equilibrium.

Let $\rho_{j, 0}$ be the price of a unit of type $j$ loan in period 0 , and $a_{j, 0}$ be the amount of type $j$ loan obtained in period 0 . Then the budget constraints for each agent can be expressed as

$$
\begin{aligned}
& c_{0}+k_{0}+q_{0} \frac{b_{0}}{P_{0}} \leq \frac{\bar{B}}{P_{0}}+y_{0}+\sum_{j \in J} \rho_{j, 0} a_{j, 0} \\
& \sum_{j \in J} \max \left(a_{j, 0}, 0\right) \leq b_{0} \\
& c\left(s_{1}\right) \leq R k_{0}+\frac{b_{0}}{P\left(s_{1}\right)}-T\left(s_{1}\right)+y_{1}-\sum_{j \in J} a_{j, 0} \min \left(j, \frac{1}{P\left(s_{1}\right)}\right)
\end{aligned}
$$

Define $h_{0}$ be the identity of the agent who is indifferent between government debt and storage:

$$
\frac{q_{0}}{P_{0}}=\frac{1}{R}\left\{h_{0} \frac{1}{P(U)}+\left(1-h_{0}\right) \frac{1}{P(D)}\right\}
$$

Without loss of generality, we assume that $j<1 / P(U)$ for all $j \in J$. We use the noarbitrage condition to determine $\rho_{j, 0}$. First, since loans of type $j \leq 1 / P(D)$ are risk-free, we have

$$
\rho_{j, 0}=\frac{j}{R}, \quad \text { for } j \leq \frac{1}{P(D)} .
$$


Next consider loans of type $j \in(1 / P(D), 1 / P(U))$. One unit of such a loan yields $j$ in state $U$ and $1 / P(D)$ in state $D$. It is thus equivalent to the following portfolio: (i) obtain $x$ units of type $j^{*}$ loan and purchase $x$ units of government debt; and (ii) make one unit of type $j^{*}$ loan, where

$$
x=\frac{j-\frac{1}{P(D)}}{\frac{1}{P(U)}-\frac{1}{P(D)}} .
$$

It follows that

$$
\rho_{j, 0}=x\left(\frac{q_{0}}{P_{0}}-\rho_{j^{*}, 0}\right)+\rho_{j^{*}, 0} .
$$

This equation can be rewritten as

$$
\rho_{j, 0}=\frac{1}{R}\left\{h_{0} j+\left(1-h_{0}\right) \frac{1}{P(D)}\right\}, \quad \text { for } j \in\left(\frac{1}{P(D)}, \frac{1}{P(U)}\right) .
$$

Now let us examine the demand and supply of each type of loans. Let us start with loans of type $j \leq j^{*}=1 / P(D)$. These loans are risk-free and their rate of return is $R$. Thus, agents $h \leq h_{0}$ are indifferent across these types of loans. For agents $h>h_{0}$, the interest rate on these loans is less than their expected rate of return on government debt. If agent $h$ obtains one unit of type $j \leq j^{*}$ loan and purchase one unit of government debt, she obtains $1 / P\left(s_{1}\right)-j$ in state $s_{1}$ in period one. Thus, the expected rate of return on such a portfolio for her is

$$
\begin{aligned}
\frac{h\left(\frac{1}{P(U)}-j\right)+(1-h)\left(\frac{1}{P(D)}-j\right)}{\frac{q_{0}}{P_{0}}-\frac{j}{R}} & =R \frac{h \frac{1}{P(U)}+(1-h) \frac{1}{P(D)}-j}{h_{0} \frac{1}{P(U)}+\left(1-h_{0}\right) \frac{1}{P(D)}-j} \\
& \leq R \frac{h \frac{1}{P(U)}+(1-h) \frac{1}{P(D)}-j^{*}}{h_{0} \frac{1}{P(U)}+\left(1-h_{0}\right) \frac{1}{P(D)}-j^{*}},
\end{aligned}
$$

for $j \leq j^{*}$ and $h>h_{0}$, where the inequality is strict for $j<j^{*}$. It follows that agents $h>h_{0}$ strictly prefers loans of type $j^{*}$ to loans of type $j<j^{*}$.

Next consider loans of type $j>j^{*}$. If agent $h$ provide such a loan, the expected rate of return is

$$
\begin{aligned}
\frac{1}{\rho_{j}}\left\{h j+(1-h) \frac{1}{P(D)}\right\} & =R \frac{h j+(1-h) \frac{1}{P(D)}}{h_{0} j+\left(1-h_{0}\right) \frac{1}{P(D)}} \\
& <R, \quad \text { for } h \leq h_{0} \text { and } j>j^{*} .
\end{aligned}
$$

That is, agents $h \leq h_{0}$ strictly prefers providing loans of type $j^{*}$ to providing loans of type $j>j^{*}$. On the other hand, if agent $h$ obtains one unit of type $j>j^{*}$ loan and purchase one unit of government debt, the expected rate of return is

$$
\frac{h\left\{\frac{1}{P(U)}-j\right\}}{\frac{q_{0}}{P_{0}}-\rho_{j}}=R \frac{h}{h_{0}},
$$


which is independent of $j$. Thus, agents $h>h_{0}$ are indifferent among loans of type $j \geq j^{*}$.

The above argument proves that only type $j^{*}$ loans are traded in equilibrium. This completes the proof.

\subsection{Marginal agents in the complete-markets specification}

Here we prove that the marginal buyers at history $D^{t}, h\left(D^{t}\right)$, is $1 /(t+2)$ in the completemarkets specification. With complete markets, we can write the present-value budget constraint for agent $h$ at history $s^{t}$ as:

$$
\sum_{u=t}^{T} \sum_{s^{u} \mid s^{t}} q\left(s^{u} \mid s^{t}\right) \frac{P\left(s^{u}\right)}{P\left(s^{t}\right)} c\left(s^{u}\right) \leq W^{h}\left(s^{t}\right),
$$

where $W^{h}\left(s^{t}\right)$ is the beginning-of-period wealth of agent $h$ in history $s^{t}$ :

$$
W^{h}\left(s^{t}\right) \equiv \frac{b^{h}\left(s_{t} \mid s^{t-1}\right)}{P\left(s^{t}\right)}+\frac{b^{h}\left(s^{t-1}\right)}{P\left(s^{t}\right)}+R k^{h}\left(s^{t-1}\right)+\sum_{s^{T} \mid s^{t}} q\left(s^{T} \mid s^{t}\right) \frac{P\left(s^{T}\right)}{P\left(s^{t}\right)}\left\{y_{T}-T\left(s^{T}\right)\right\},
$$

and $q\left(s^{u} \mid s^{t}\right)$ is defined as

$$
q\left(s^{u} \mid s^{t}\right)=q\left(s_{t+1} \mid s^{t}\right) \times \cdots \times q\left(s_{u} \mid s^{u-1}\right) .
$$

Note that at each history $s^{t}, W^{h}\left(s^{t}\right)$ is either 0 or some constant $\bar{W}\left(s^{t}\right)>0$, which does not depend on $h$.

Let us restrict attention to the histories of the form $s^{t}=D^{t}, t=0, \ldots, T-1$. Note that

$$
\begin{aligned}
W^{h}\left(D^{t+1}\right) & = \begin{cases}0, & \text { for } h>h\left(D^{t}\right), \\
\bar{W}\left(D^{t+1}\right), & \text { for } h \leq h\left(D^{t}\right),\end{cases} \\
W^{h}\left(D^{t}, U\right) & = \begin{cases}0, & \text { for } h \notin\left[h\left(D^{t}\right), h\left(D^{t-1}\right)\right], \\
\bar{W}\left(D^{t}, U\right), & \text { for } h \in\left[h\left(D^{t}\right), h\left(D^{t-1}\right)\right] .\end{cases}
\end{aligned}
$$

Furthermore, we have

$$
\begin{aligned}
h\left(D^{t}\right) \bar{W}\left(D^{t+1}\right) & =\left\{h\left(D^{t-1}\right)-h\left(D^{t}\right)\right\} \bar{W}\left(D^{t}, U\right) \\
& =R^{t+1} y_{0}+R^{-T+t+1} y_{T} .
\end{aligned}
$$

It follows that

$$
\frac{\bar{W}\left(D^{t+1}\right)}{\bar{W}\left(D^{t}, U\right)}=\frac{h\left(D^{t-1}\right)-h\left(D^{t}\right)}{h\left(D^{t}\right)}
$$


On the other hand,

$$
\begin{aligned}
\bar{W}\left(D^{t}\right) & =\frac{q\left(U \mid D^{t}\right) P\left(D^{t}, U\right)}{P\left(D^{t}\right)} \bar{W}\left(D^{t}, U\right) \\
& =\frac{q\left(D \mid D^{t}\right) P\left(D^{t+1}\right)}{P\left(D^{t}\right)} \bar{W}\left(D^{t+1}\right)
\end{aligned}
$$

It follows that

$$
\frac{\frac{q\left(U \mid D^{t}\right) P\left(D^{t}, U\right)}{P\left(D^{t}\right)}}{\frac{q\left(D \mid D^{t}\right) P\left(D^{t+1}\right)}{P\left(D^{t}\right)}}=\frac{h\left(D^{t-1}\right)-h\left(D^{t}\right)}{h\left(D^{t}\right)} .
$$

The identity of the marginal agent, $h\left(D^{t}\right)$, satisfies

$$
\frac{h\left(D^{t}\right) \frac{1}{P\left(D^{t}, U\right)}}{\frac{q\left(U \mid D^{t}\right)}{P\left(D^{t}\right)}}=\frac{\left(1-h\left(D^{t}\right)\right) \frac{1}{P\left(D^{t+1}\right)}}{\frac{q\left(D \mid D^{t}\right)}{P\left(D^{t}\right)}},
$$

which can be rewritten as

$$
\frac{h\left(D^{t}\right)}{1-h\left(D^{t}\right)}=\frac{\frac{q\left(U \mid D^{t}\right) P\left(D^{t}, U\right)}{P\left(D^{t}\right)}}{\frac{q\left(D \mid D^{t}\right) P\left(D^{t+1}\right)}{P\left(D^{t}\right)}} .
$$

Thus we obtain

$$
\frac{h\left(D^{t}\right)}{1-h\left(D^{t}\right)}=\frac{h\left(D^{t-1}\right)-h\left(D^{t}\right)}{h\left(D^{t}\right)}
$$

For $t=0$, this becomes

$$
\frac{h_{0}}{1-h_{0}}=\frac{1-h_{0}}{h_{0}}
$$

which implies $h_{0}=1 / 2$. As a result, we obtain $h\left(D^{t}\right)=1 /(t+2)$. This completes the proof.

\section{References}

[1] Bassetto, Marco. 2002. "A game-theoretic view of the fiscal theory of the price level." Econometrica, 70, 2167-2195.

[2] Bassetto, Marco and Andrew Butters. 2010. "What is the relationship between large deficits and inflation in industrialized countries?" Economics Perspectives: Federal Reserve Bank of Chicago, 83-98.

[3] Braun, R. Anton and Douglas Joines. 2011. "The implications of a greying Japan for government policy." Unpublished manuscript. 
[4] Bi, Huixin. 2011. "Sovereign default risk premia, fiscal limits and fiscal policy." Unpublished Manuscript.

[5] Cochrane, John H. 2001. "Long term debt and optimal policy in the fiscal theory of the price level." Econometrica, 69, 69-116.

[6] Davig, Troy, Eric M. Leeper and Todd B. Walker. 2011. "Inflation and the fiscal limit." European Economic Review, 55, 31-47.

[7] Fostel, Ana, and John Geanakoplos. 2008. "Leverage cycles and the anxious economy." American Economic Review, 98, 1211-1244.

[8] Galati, Gabriele, Peter Heemeijer and Richhild Moessner. 2011. "How do inflation expectations form? New insights from a high-frequency survey." Bank for International Settlements Working Papers, No. 349.

[9] Geanakoplos, John. 2003. "Liquidity, default, and crashes: Endogenous contracts in general equilibrium." In Advances in Economics and Econometrics: Theory and Applications, Eighth World Conference, Vol. 2, 170-205. Econometric Society Monographs.

[10] Geanakoplos, John. 2010. "The leverage cycle." In NBER Macroeconomics Annual 2009, ed. Daron Acemoglu, Kenneth Rogoff, and Michael Woodford, 1-65. University of Chicago Press.

[11] Imrohoroglu, Selahattin and Nao Sudo. 2010. "Productivity and fiscal policy in Japan: Short term forecasts from the standard growth model." IMES Discussion Paper Series 10-E-23, Institute for Monetary and Economic Studies, Bank of Japan.

[12] "Anticipating credit events using credit default swaps, with an application to sovereign debt crises." IMF Working Paper, WP/03/106.

[13] Leeper, Eric M. 1991. "Equilibria under 'active' and 'passive' monetary policies." Journal of Monetary Economics, 27, 129-147.

[14] Nieto Parra, Sebastián. 2008. "Who saw sovereign debt crises coming?" OECD Development Centre Working Paper No. 274.

[15] Reinhart, M. Carmen and Kenneth Rogoff. 2010. "From financial crash to debt crisis." NBER Working Papers, No. 15795.

[16] Sims, Christopher A. 1994. "A simple model for study of the determination of the price level and the interaction of monetary and fiscal policy." Economic Theory, 4, 381-399. 
[17] Woodford, Michael. 1995. "Price level determinacy without control of a monetary aggregate." Carnegie-Rochester Conference Series on Public Policy, 43, 1-46. 
Table 1: Inflation rates (\%) and marginal buyers in the two-period model

\begin{tabular}{l|ccc|c}
\hline \hline & $\pi_{-1}$ & $\pi_{0}$ & $\pi(D)$ & $h_{0}$ \\
\hline (1) complete markets & -1.96 & 30.72 & 47.06 & 0.5 \\
(2) no borrowing & -1.96 & 25.57 & 53.09 & 0.56 \\
$(3)$ leverage & -1.96 & 9.46 & 75.62 & 0.79 \\
\hline \hline
\end{tabular}

Table 2: Inflation rates (\%) and marginal buyers in the three-period model

\begin{tabular}{l|cccc|cc}
\hline \hline & $\pi_{-1}$ & $\pi_{0}$ & $\pi(D)$ & $\pi\left(D^{2}\right)$ & $h_{0}$ & $h(D)$ \\
\hline (1) complete markets & -1.96 & 17.65 & 22.55 & 30.72 & 0.50 & 0.33 \\
(2) leverage & -1.96 & -1.09 & 10.86 & 71.89 & 0.94 & 0.75 \\
\hline \hline
\end{tabular}

Table 3: Log yields in the five-period model (\%)

\begin{tabular}{l|ccccc}
\hline \hline & $\rho_{-1}$ & $\rho_{0}$ & $\rho(D)$ & $\rho\left(D^{2}\right)$ & $\rho\left(D^{3}\right)$ \\
\hline (1) complete markets & 1.98 & 6.34 & 14.84 & 34.68 & 104.15 \\
(2) leverage & 1.98 & 1.98 & 2.05 & 5.04 & 38.70 \\
\hline \hline
\end{tabular}




\section{Table 4}

\section{Holdings of U.S. Government Debt}

End of Calendar year 2010

\begin{tabular}{lcc}
\hline \hline & $\begin{array}{l}\text { Amount } \\
\text { (trillion \$) }\end{array}$ & $\begin{array}{l}\text { Fraction } \\
(\%, \text { net of govt) }\end{array}$ \\
\hline Total & 14.03 & \\
Government & 6.17 & \\
Individuals and non-financial companies & 1.41 & 12.4 \\
Domestic Financial Institutions & 5.38 & 47.2 \\
$\quad$ Private & 1.82 & 16.0 \\
$\quad$ Public & 2.44 & 21.4 \\
$\quad$ Central Bank & 1.11 & 9.8 \\
Foreign sector & 4.44 & 38.9 \\
\hline \hline
\end{tabular}

\section{Holdings of Japanese Government Debt}

End of fiscal year 2008

\begin{tabular}{lcc}
\hline \hline & $\begin{array}{l}\text { Amount } \\
\text { (trillion yen) }\end{array}$ & $\begin{array}{c}\text { Fraction } \\
\text { (\%, net of govt) }\end{array}$ \\
\hline Total & 936.63 & \\
Government & 114.04 & \\
Individuals and non-financial companies & 75.88 & 9.2 \\
Domestic Financial Institutions & 687.45 & 83.6 \\
$\quad$ Private & 354.27 & 43.1 \\
$\quad$ Public & 268.06 & 32.6 \\
$\quad$ Central Bank & 65.12 & 7.9 \\
Foreign sector & 59.26 & 7.2 \\
\hline \hline
\end{tabular}


Table 5

Spreads on Mortgage Rates over

Government Debt in U.S. and Japan

Data collected on October 24, 2011*

\begin{tabular}{lcc}
\hline \hline & $\begin{array}{c}\text { U.S. } \\
\text { (Percentage) }\end{array}$ & $\begin{array}{c}\text { Japan } \\
\text { (Percentage) }\end{array}$ \\
\hline 1- Year ARM & 2.84 & 0.86 \\
5/1-year ARM & 1.92 & 1.22 \\
15-Year Fixed & 0.5125 & n.a. \\
20-Year Fixed & n.a. & 0.47 \\
30-Year Fixed & 1.06 & 0.46 \\
\hline \hline
\end{tabular}

${ }^{*}$ Government debt yields and

U.S. Mortgage rates are from Bloomberg.

Japan Mortgage rates are from Shinsei Bank. 

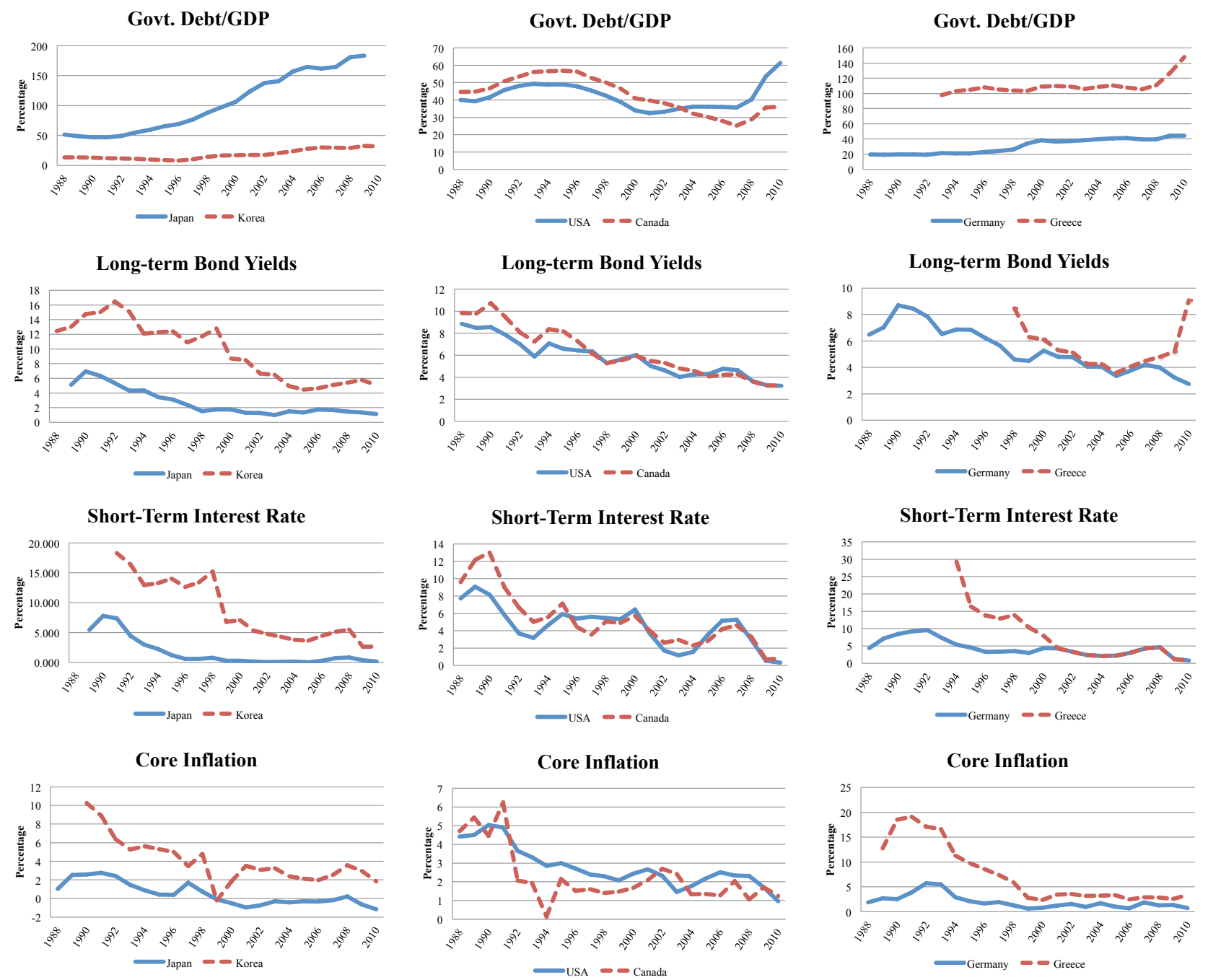

Figure 1: Pairwise comparisons of countries with large and increasing deb-GDP ratios and countries without. 


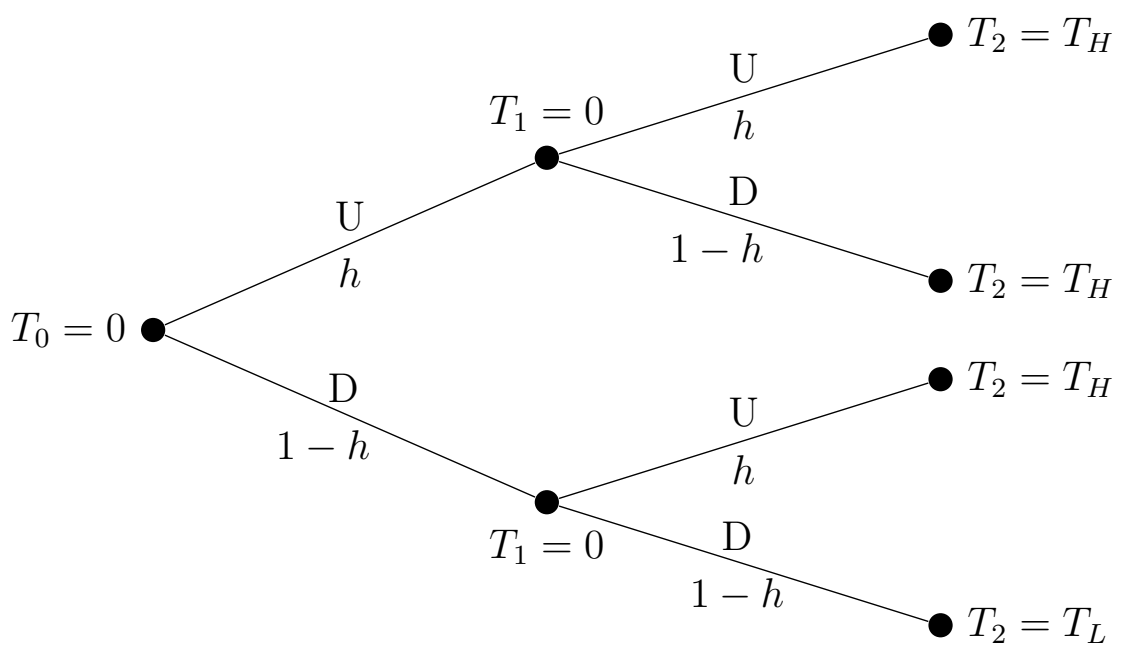

Figure 2: The event tree for the case where $T=2$ 


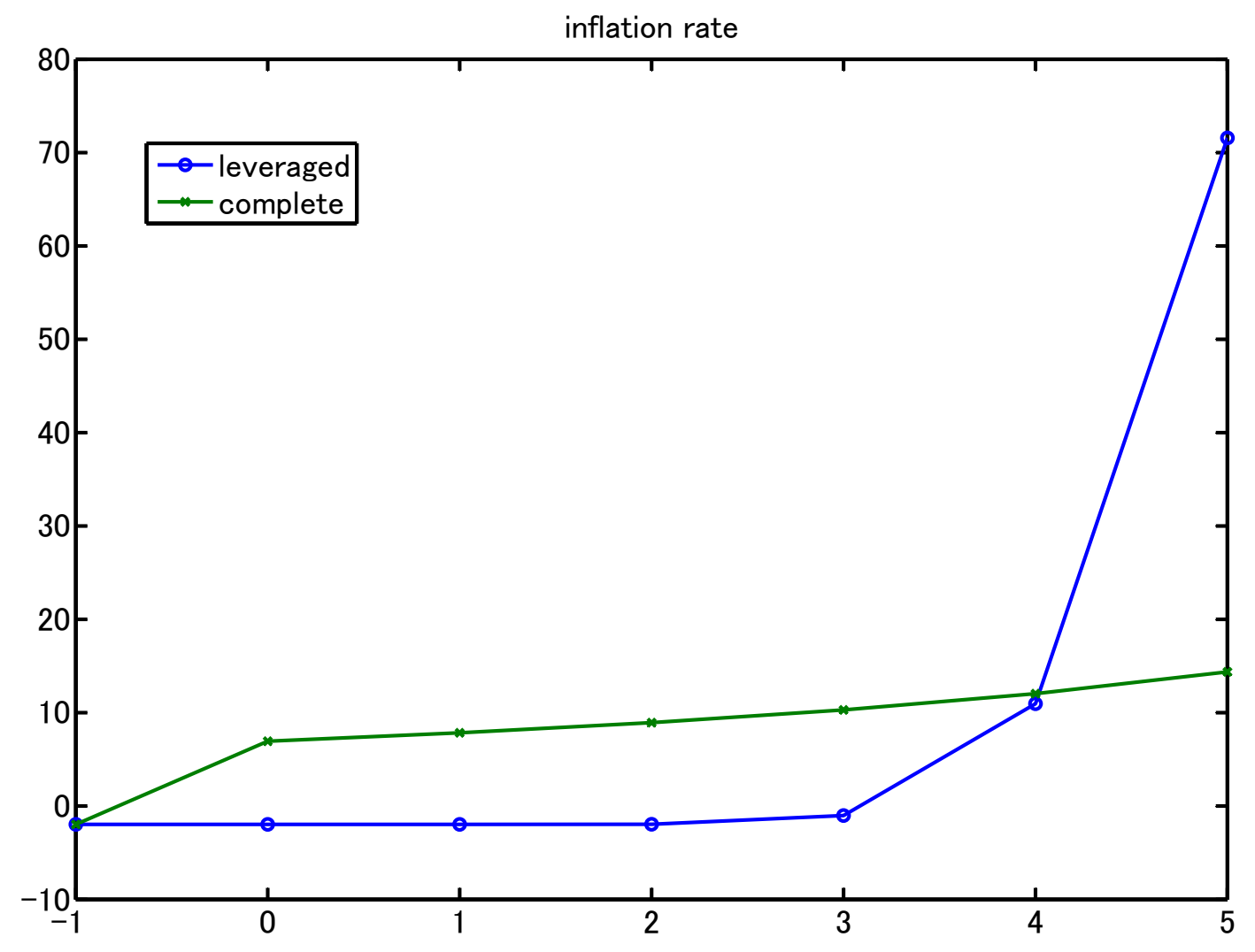

Figure 3: The inflation rate for the complete markets and leverage specifications when $T=5$. 